\title{
Trabalho intermitente: uma análise comparada ${ }^{1}$
}

\author{
Leandro Luciano Silva Ravnjak²
}

Giovana Maria Mendes Rodrigues ${ }^{3}$

Victor Manoel Rangel Soares ${ }^{4}$

\begin{abstract}
Resumo
O contrato de trabalho é caracterizado pela indeterminação de prazo, a fim de assegurar a especialização do trabalhador, respeitando o princípio da continuidade do vínculo de emprego e a estabilidade das relações jus laborais. Com a entrada em vigor da denominada "Reforma Trabalhista", a lógica da continuidade é flexibilizada com o contrato de trabalho intermitente, reconhecendo o vínculo empregatício mesmo com a presença da eventualidade. O Objetivo do presente texto é evidenciar os pontos de convergência e de distanciamento do trabalho intermitente no Brasil e nos demais países estrangeiros, bem como a precarização da relação de emprego trazida pelo trabalho intermitente. Optou-se pela pesquisa qualitativa, de caráter exploratório e comparado.
\end{abstract}

\section{Palavras-chave \\ Trabalho Intermitente; Reforma Trabalhista; Direito Comparado}

Intermittent work: a comparative analysis

\begin{abstract}
The standard employment contract is featured with indefinite period, aiming to secure a better stability and specialization of the worker. The intermittent employment contract comes up with the Labor Reform, and breaks up with all of this logic, recognizing the employment bond even though one of the factual-legal requirements is missing, the non-eventuality. The goal of this paper is to show the convergence and distance points among the Brazilian intermittent work and the intermittent work in other countries, and show how the intermittent work undermines the employment relationship.
\end{abstract}

\section{Keywords}

Intermittent work; Labor Reform; Comparative Law.

Artigo enviado em julho de 2021

Artigo aprovado em setembro de 2021 


\section{Introdução}

O trabalho é inerente à natureza humana, pois o homem sempre trabalhou, desde os tempos mais primitivos com a caça, com a pesca e para produção de abrigos, até na perspectiva mais moderna, com a utilização de tecnologias variadas para os mesmos fins, bem como para alcançar o lazer e a produção de outros bens e serviços. Assim, o modo como o trabalho é realizado pela sociedade sofreu diversas modificações: a escravidão inicialmente, por exemplo, representava punição e submissão aos povos vencidos nas batalhas. Já o período industrial é marcado pela Revolução Industrial e a mudança nos sistemas produtivos, com intensificação na exploração da mão de obra operária, jornadas exaustivas e salários baixos para a simples reprodução da classe trabalhadora.

Os movimentos operários e as pressões por melhores condições de trabalho, especialmente no contexto da Revolução Industrial, tencionam o Estado ao reconhecimento de direitos trabalhistas em textos normativos.

As primeiras regulamentações se encontram no âmbito internacional, entre estes textos, destaca-se a Constituição Mexicana de 1917, que inovou ao alçar os direitos trabalhistas ao patamar de direitos fundamentais. No Brasil, o Direito do Trabalho é regulamentado pela Constituição Federal de 1988 e pela Consolidação das Leis do Trabalho (CLT), além de outras legislações esparsas pelo ordenamento jurídico.

Em 2017, o país institucionaliza um movimento de desestruturação do Direito do Trabalho, marcado pela aprovação da Lei Federal 13.467, de 13 de julho de 2017, que impõe novos padrões de relação de emprego, em especial a possibilidade de um contrato de trabalho intermitente. Segundo o artigo 443, $\$ 3^{\circ}$ da Consolidação das Leis do Trabalho (CLT), o contrato de trabalho intermitente pode ser conceituado como aquele "[...] no qual a prestação de serviços, com subordinação, não é contínua, ocorrendo com a alternância de períodos [...]". Tal mudança implica no reconhecimento da relação de emprego 
sem a presença de um dos requisitos essenciais para esta configuração - qual seja, a não eventualidade. Assim, mesmo que a relação de emprego seja eventual, é reconhecido o vínculo empregatício, caracterizando o trabalho intermitente.

A nova modalidade de contrato incorporado pela reforma trabaIhista não tem paradigma no Brasil, tendo sido trazida ao ordenamento jurídico pátrio sob a influência de diversos países como Portugal, Reino Unido, Itália e Espanha, o que justifica a realização do presente estudo.

\section{Contextualização do trabalho intermitente}

A lei $n^{\circ} 13.467$, de julho de 2017, foi denominada como Reforma Trabalhista por trazer diversas modificações no texto consolidado, o que implicou na transformação das relações laborais, apresentando novos conceitos e mitigando direitos. Entre as inovações destaca-se o trabalho intermitente que, segundo o texto consolidado, tem a seguinte definição:

Art. 443. O contrato individual de trabalho poderá ser acordado tácita ou expressamente, verbalmente ou por escrito, por prazo determinado ou indeterminado, ou para prestação de trabalho intermitente

§3o Considera-se como intermitente o contrato de trabalho no qual a prestação de serviços, com subordinação, não é contínua, ocorrendo com alternância de períodos de prestação de serviços e de inatividade, determinados em horas, dias ou meses, independentemente do tipo de atividade do empregado e do empregador, exceto para os aeronautas, regidos por legislação própria. (BRASIL, 1943).

A aludida modalidade de contrato é caracterizada como uma prestação de serviços, com subordinação, porém não contínua, ocorrendo de forma alternada, sem o rompimento do vínculo trabalhista. Destaca-se, ainda, que não há limitação em relação à atividade praticada, podendo ser realizada em qualquer setor, seja no comércio, escolas ou nas linhas de produção industriais. A única atividade que possui limitação em relação a esse tipo de contrato de trabalho é a categoria aeronáutica. 
Segundo Delgado (2017), existem cinco elementos fático-jurídicos que configuram o vínculo empregatício: pessoa física, pessoalidade, não eventualidade, onerosidade e subordinação. Entretanto, após a Reforma Trabalhista, surge o instituto do trabalho intermitente, no qual o vínculo empregatício é caracterizado mesmo com a ausência do elemento "não eventualidade".

A configuração do contrato de trabalho intermitente pressupõe a habitualidade na prestação do serviço, que poderão ser realizados em alternação com períodos de inatividade de horas, dias ou até meses. Assim, o trabalho intermitente cria uma exceção ao elemento da não eventualidade para considerar empregado aquele trabalhador que, em tese, seria eventual. (BRITO, 2017).

Entende-se que o trabalhador ficará à disposição do empregador, pois aquele somente será convocado ao trabalho quando ocorrer necessidade e aumento da demanda. Além disso, o empregado será remunerado apenas pelas horas efetivamente trabalhadas, não sendo garantida uma remuneração mínima, uma vez que não faz jus ao recebimento pelas horas sob aviso do empregador. (D'AMORIM, 2018).

É importante ressaltar que o texto consolidado atribui total liberdade para os empregadores realizarem a contratação do trabalho intermitente, podendo escolher entre remunerar apenas as horas trabalhadas ou predefinir uma jornada de trabalho.

Essa modalidade contratual é, seguramente, uma das mais claras manifestações de superexploração do trabalho humano, pois equipara o trabalhador a uma máquina descartável, colocando, pois, em xeque o projeto constitucional brasileiro de construção da cidadania, da melhoria das condições sociais dos trabalhadores e de uma sociedade mais livre, justa e solidária. (LEITE, 2018).

O contrato de trabalho intermitente, muitas das vezes, depende da demanda do empregador, pois, os trabalhadores somente são convocados a partir do surgimento da necessidade da mão-de-obra. "[...] este aspecto gera uma incerteza para o trabalhador, além de um forte 
impacto social, na medida em que reduz as contribuições previdenciárias e os direitos trabalhistas". (TEIXEIRA, 2017, p.66).

Parte da doutrina entende que esse contrato possui aspectos aleatórios e, por esse motivo, transfere parte do risco do empreendimento ao empregado.

É inegável que esse tipo de contrato, por conter um forte elemento aleatório, transfere parte do risco empresarial, mesmo que mínimo, ao empregado, pois este, para auferir sua remuneração, fica dependente das variações do setor econômico [...]. (BRITO, 2017).

O período de inatividade ocorre entre a prestação de um serviço e a convocação para um outro. Nesse período, o empregado poderá exercer qualquer tipo de atividade para outros empregadores, sejam eles do mesmo ramo de atividade ou não, podendo ser utilizado o contrato intermitente ou outro de qualquer modalidade. (JORGE NETO; CAVALCANTE, 2019).

\section{Requisitos legais para configuração do trabalho intermitente}

O artigo 452- A da CLT, incluído pela Lei $n^{\circ} 13.467 / 17$, estabelece que o contrato de trabalho intermitente deve ser realizado de forma escrita, não se admitindo a forma verbal ou tácita. Segundo entendimento de Brito (2017), caso o contrato não seja realizado na forma prevista pela lei, ocorrerá uma interpretação restritiva e o contrato será considerado como de prazo indeterminado e não-eventual, de modo que a remuneração será de acordo com a jornada de 8 horas diárias e o regime de 44 horas semanais.

O referido artigo prevê a garantia de um salário-hora mínimo ao trabalhador intermitente. Assim, sua remuneração não poderá ser inferior a hora do salário mínimo, e também ao valor pago para aqueles funcionários que exercem a mesma função, sejam eles de trabalhadores intermitentes ou não.

A forma de convocação para o trabalho também é regulamentada por lei, prevista no artigo $452-\mathrm{A}, \$ 1^{\circ}$ e $\$ 2^{\circ}$. O trabalhador será convoca- 
do com antecedência de três dias corridos, momento em que deverá ser informado da jornada de trabalho a ser cumprida. A comunicação deverá ser feita por um meio eficaz, como e-mail ou pelo celular. Ao tomar conhecimento da convocação, o empregado possui 1(um) dia útil para manifestar seu interesse de realizar ou não o serviço. Findo o prazo, entende-se a recusa por parte do trabalhador.

Repise-se que a recusa de oferta de serviço no contrato de trabalho intermitente não descaracteriza o elemento fático-jurídico da subordinação, continuando presentes os elementos pessoa física, pessoalidade, não-eventualidade e onerosidade.

[...] o $\$ 3^{\circ}$ do art.452-A estipula que o obreiro intermitente continua submetido ao poder diretivo patronal, contra face da subordinação jurídica. Tanto é assim que o empregado poderá infringir os deveres de lealdade e boa-fé decorrentes do contrato de trabalho e, mesmo nos períodos de inatividade, não deverá incidir nas justas causas obreiras do art.482 da CLT [...]. (BRITO, 2017).

Nota-se que reiteradas recusas podem fazer com que o empregado não seja mais chamado, uma vez que o empregador procurará por aqueles que possuem mais disponibilidade, ficando caracterizada a presença da subordinação no contrato intermitente.

[...] § 4o Aceita a oferta para o comparecimento ao trabalho, a parte que descumprir, sem justo motivo, pagará à outra parte, no prazo de trinta dias, multa de 50\% (cinquenta por cento) da remuneração que seria devida, permitida a compensação em igual prazo. (BRASIL, 1943).

O $4^{\circ}$ do artigo estabelece uma penalidade, na forma de multa, para ambas as partes do contrato que não cumprirem com seus deveres. Quando o empregado aceitar expressamente a realização da prestação de serviço e não comparecer ao local e horário determinado, deverá arcar com multa calculada em 50\% sob o valor de sua remuneração. Assim também ocorrerá com o empregador que não forneça as condições para a realização do serviço. Para ambos, o prazo para pagamento será de 30 dias. 
De acordo com o previsto no $\$ 5^{\circ}$, do artigo 452-A da CLT, não será considerado tempo a disposição do empregador o período de inatividade, podendo o trabalhador realizar outros tipos de serviços, independentemente do tipo de contrato. Segundo Jorge Neto e Cavalcante (2017), verifica-se um grande desequilíbrio na relação contratual, pois o empregador não é mais responsável pelos períodos de repouso e higiene, por exemplo, evidenciando a precarização do trabalho intermitente.

Quanto aos pagamentos devidos ao obreiro, o $\$ 6^{\circ}$, do artigo 452 da CLT, indica que serão realizados imediatamente após o término de cada período de prestação de serviço.

$\S 6^{\circ}$ Ao final de cada período de prestação de serviço, o empregado receberá o pagamento imediato das seguintes parcelas:

I - remuneração;

II - férias proporcionais com acréscimo de um terço

III - décimo terceiro salário proporcional;

IV - repouso semanal remunerado; e

V - adicionais legais. (BRASIL, 1943).

O empregador deverá também recolher os valores referentes à contribuição previdenciária e ao depósito do Fundo de Garantia do Tempo de Serviço (FGTS), tendo como referência os valores pagos no período mensal. O empregador deve, ainda, apresentar ao trabalhador o comprovante de quitação destas obrigações. (BRASIL, 1943).

O trabalhador intermitente, após 12 meses de prestação de serviços, terá o direito de usufruir de um período de férias de 1 mês, não podendo ser convocado para o trabalho pelo mesmo empregador durante esse período.

Destaca-se que, durante o período de férias, o empregado não fará jus a qualquer remuneração, já que o valor devido a título de férias foi pago ao fim de cada período de prestação de serviços. Logo, é necessário que o trabalhador preste serviços a outros empregadores para que possua alguma renda durante suas férias, o que implica em prejuízo ao gozo efetivo de suas férias e descanso. 


\section{Trabalho intermitente na modalidade comparada}

Embora a Lei ${ }^{\circ} 13.467$ de julho de 2017 tenha trazido a modalidade do trabalho intermitente para o ordenamento jurídico brasileiro, o trabalho intermitente não se trata de uma inovação do direito pátrio.

Segundo Columbu (2017), a referida modalidade já estava presente em outros ordenamentos jurídicos, tais como o italiano - no qual é denominada lavoro intermitente -, o português - admitindo duas submodalidades de contrato: o trabalho alternado e o trabalho à chamada -, o inglês, onde é chamado zero hour contract e o espanhol - trabajo discontínuo.

Cada um desses países regulamentou de forma distinta os contratos de trabalho intermitente, podendo-se, contudo, verificar pontos convergentes entre os regramentos estrangeiros e o regramento nacional.

\section{Trabalho intermitente italiano}

Na Itália, o lavoro intermitente aparece pela primeira vez com o Decreto Legislativo 276/2003, também conhecido como Lei Biaggi ou Reforma Biaggi (ITÁLIA, 2003). A Reforma Biaggi teve grande importância para o Direito Italiano, uma vez que, a partir dela as relações laborais passaram a ser dotadas de "[...] intensas doses de flexibilidade" (COLUMBU, 2017). No que se refere à regulamentação do trabalho intermitente italiano, a referida Lei Biaggi foi parcialmente revogada pelo Decreto Legislativo 81/2015, também chamado de "Jobs Act". O trabalho intermitente encontra-se disciplinado nos artigos 13 a 18.

Nos termos do artigo 13 do Decreto Legislativo 81/2015, entende-se por trabalho intermitente o contrato “[...] através do qual o trabalhador se coloca à disposição de um empregador que pode utilizar a prestação de trabalho deste de forma descontínua ou intermitente, segundo as exigências indicadas pela contratação coletiva, com referência também à possibilidade de desempenhar as prestações em períodos pré-estabelecidos ao longo da semana, do mês ou do ano [...]" (COLUMBU, 2017).

Nota-se a similaridade do instituto do trabalho intermitente italiano com o brasileiro, mormente em razão da forma descontínua, eventual, 
de prestação do trabalho por parte do obreiro. Assim, o trabalhador se coloca à disposição da eventual "chamada" do empregador (por isso a referida modalidade também é conhecida como Lavoro a chiamata).

$\mathrm{Na}$ Itália, somente os trabalhadores que têm menos de 25 e mais de 55 anos podem se submeter à modalidade do trabalho intermitente. Nesse caso, a ratio legis reside na intenção de fomentar a readmissão no mercado de trabalho da parcela que mais se encontra afetada pelo desemprego.

Demais isso, segundo o Decreto Legislativo 81/2015, “[...] cada trabalhador somente poderá prestar para o mesmo empregador o trabaIho intermitente pelo período de 400 dias a cada três anos civis [...]" (KALED, 2019). Superados os três anos, o contrato deixa de ser eventual e passa a ser integral e por prazo indeterminado, excetuando-se os setores de turismo, exercícios públicos e entretenimento.

Além disso, “[...] a prestação [do trabalho] poderá ser em períodos predeterminados durante a semana, mês ou ano, e, caso não haja negociação coletiva, o Ministério do Trabalho será o responsável por verifıcar seu cabimento" (KALED, 2019).

O artigo $14, \S 1^{\circ}$, estabelece um limite para a utilização do contrato intermitente, nessa modalidade, não podendo ser contratados trabalhadores para:

[...] substituir trabalhadores em greve; para aquelas empresas que durante os seis meses que precedem a contratação tiveram uma dispensa coletiva de trabalhadores com as mesmas funções, interessadas pela nova contratação, ou tiveram a suspensão da produção, redução salarial, etc.; e também é proibida a contratação de trabalhadores 'a chiamata' para aquelas empresas que não produziram a certificação do quadro relativo às medidas de proteção da saúde e segurança na empresa. (COLUMBU, 2017).

A partir da visão geral acerca do trabalho intermitente no ordenamento jurídico italiano, faz-se necessário mencionar as duas espécies presentes dentro dessa modalidade laboral, quais sejam, com ou sem garantia de disponibilidade. 
Assim como acontece no Brasil, o contrato de trabalho intermitente deve ser escrito, ainda que somente para fins de comprovação de sua existência (KALED, 2019). Além disso, deve constar no instrumento contratual se a prestação de trabalho se dará por período fixo ou indefinido. Tal determinação encontra-se positivada no artigo 15, que estabelece os requisitos formais para o contrato intermitente:

a) duração e hipóteses, objetivas e subjetivas, que autorizam a estipulação do contrato conforme art. 13;

b) cabimento e modalidade da disponibilidade, eventualmente garantida pelo trabalhador, e do relativo tempo de pré-aviso da chamada do trabalhador, que não pode ser inferior a um dia útil;

c) tratamento econômico e normativo que será aplicado ao trabaIhador para a prestação de trabalho desenvolvida e relativa indenização de disponibilidade, quando prevista;

d) formas e modalidades, com as quais o empregador tem o direito de solicitar a execução da prestação de trabalho, bem como métodos de detecção de desempenho;

e) periodicidade e modalidade de pagamento da retribuição e da indenização de disponibilidade;

f) medidas de segurança necessárias em relação ao tipo de atividade prevista em contrato.

Prevê também que, ressalvadas previsões mais favoráveis dos contratos coletivos, o empregador deve informar com periodicidade anual, aos representantes sindicais empresariais ou à representação sindical unitária, sobre a utilização dos contratos de trabalho intermitentes. (NOGUEIRA, 2017).

Na primeira espécie, o trabalho com garantia de disponibilidade, está-se diante de um contrato no qual o trabalhador alterna entre momentos de prestação laboral e momentos à disposição do empregador. 
Assim, o empregado garante a sua disponibilidade para atender às demandas e exigências do empregador (COLUMBU, 2017). A contrapartida a essa garantia é o direito à indenização pelo tempo à disposição.

Segundo Columbu (2017):

A importância devida a título de indenização da disponibilidade é determinada pela contratação coletiva, mas - em nenhum caso - poderá ser inferior ao mínimo fixado periodicamente pelo Ministério do Trabalho (COLUMBU, 2017).

Ocorre que, nos períodos em que acontece a prestação do serviço, o obreiro encontra-se sob o regime do contrato de emprego. Contudo, o referido regime é suspenso, restando o estatuto protetivo em stand-by.

"A recusa injustificada de atender à chamada pode constituir motivo de dispensa e levar à restituição da quota de indenização de disponibilidade relativa ao período sucessivo à recusa" (NOGUEIRA, 2017).

Já em relação aos trabalhadores que não pactuaram assegurar a garantia de disponibilidade ao empregador, esses não farão jus a nenhuma das garantias normativas e econômicas nos períodos de prestação laboral. Lado outro, não serão penalizados por não atender eventuais chamados do empregador.

Neste caso, desaparecem os traços marcantes do vínculo de emprego porque a obrigação do trabalhador consiste apenas em decidir quando ativar o vínculo, ou seja, atendendo à solicitação do empregador, logo, limitadamente a este período - em que ele exerce a prestação laboral - poderíamos falar em trabalho subordinado, já que nos momentos fora da prestação a relação de emprego não existe. (COLUMBU, 2017).

Segundo Columbu (2017), nesse sentido, a doutrina italiana chegou a se referir ao trabalho intermitente sem garantia de disponibilidade a um não contrato, ficando as partes restritas a negociar meramente a possibilidade da vontade, o que não caracterizaria um vínculo jurídico. 
De modo semelhante ao aplicado no Brasil, o artigo 17 do Jobs Act estabelece os princípios de não discriminação aplicáveis ao trabaIhador intermitente.

Em linhas gerais, determina que o trabalhador não poderá receber tratamento normativo e econômico inferior ao do trabalhador de mesmo nível. Ao trabalhador intermitente, ainda é garantido tratamento previdenciário proporcional à sua prestação laborativa.

A lei estabelece, no art. 17, quais são os princípios de não discriminação aplicáveis com relação ao trabalhador intermitente, ou seja: o trabalhador intermitente não pode receber, para os períodos trabalhados e em igualdade de funções desenvolvidas, um tratamento econômico e normativo complexivamente menos favorável a respeito do trabalhador de mesmo nível $\left(\$ 1^{\circ}\right)$; o tratamento econômico, normativo e previdenciário do trabalhador intermitente deve ser proporcional em razão da prestação laborativa efetivamente desenvolvida, em particular no que diz respeito à retribuição global e de cada componente desta, inclusive férias e em matéria de doença e infortúnio, licença gestante e licença-paternidade $\left(\S 2^{\circ}\right)$. (NOGUEIRA, 2017).

Cabe salientar que o instituto do trabalho intermitente, na Itália, manteve-se numa posição marginal em relação às demais modalidades de emprego, não tendo se tornado uma modalidade difundida de contratação de mão-de-obra (COLUMBU, 2017).

Já no Brasil, os próximos anos serão determinantes para o diagnóstico dessa modalidade de contratação, que, preliminarmente fortalece o projeto de precarização da classe trabalhadora.

\section{Trabalho intermitente português}

A figura contratual do trabalho intermitente não era totalmente desconhecida no ordenamento jurídico português. Previsto na Lei $n^{\circ}$ 4 de 7 de fevereiro de 2008 (Lei $n^{\circ}$ 4/2008), a modalidade do trabalho intermitente foi regulamentada como o regime específico para os profissionais do espetáculo, admitindo que as partes do contrato 
desses profissionais poderiam convencionar o exercício intermitente da prestação de serviço sempre que o espetáculo público não apresentasse a continuidade.

O contrato intermitente deveria ser realizado de forma escrita, e nele está descrito os períodos de trabalho efetivo e os valores pagos durante o período de prestação do serviço e da inatividade. Além disso, permite-se que o contrato de prestação de trabalho intermitente seja realizado antes ou durante a prestação do serviço. (Art. 8 da Lei $n^{\circ}$ 4/2008).

Com a promulgação do Código do Trabalho de 2009 (Lei n 7/2009) o trabalho intermitente português é ampliado e passa a ser utilizado não somente pelos profissionais do espetáculo. Os artigos 157 a 160 da referida lei preveem a regulamentação desse tipo de contrato, surgidas após a crise do direito do trabalho com a ideia central de flexibilização da relação de emprego, buscando atender às necessidades dos empregados que exercem atividades de forma descontínuas.

A flexibilidade [...] surge como uma possibilidade de intervir estrategicamente no mercado de trabalho, aumentando o número de pessoas que podem obter um emprego, quer pela criação de novos postos de trabalho, quer pela repartição dos já existentes, surgindo assim como benefício dos próprios trabalhadores, que se viriam integrados na vida laboral, ainda que não nas desejadas condições de uma relação laboral típica. [...] (MARTINS, 2012).

Ocorre que, se por um lado a flexibilização apresenta estratégias de trazer para a formalidade aqueles trabalhadores alijados do conjunto de benefícios sociais ofertados pelo estado, por outro lado, esse movimento de flexibilização, legitimado, e às vezes incentivado pelo Estado, precariza ainda mais a condição da classe trabalhadora, e, na figura do trabalho intermitente não é diferente.

O contrato de trabalho intermitente português admite duas submodalidades de contrato, a saber, o trabalho alternado e o contrato à chamada. Observa-se, dentre elas, uma grande diferença dos reflexos 
nas relações jus laborais e o regime jurídico adotado. Assim, as partes do contrato poderão escolher qual contrato estabelecer, desde que observados os requisitos mínimos legais.

O trabalho alternado encontra-se disposto na primeira parte do Art. 159, n¹ da Lei n 7/2009: “[...] as partes estabelecem a duração da prestação de trabalho, de modo consecutivo ou interpolado, bem como o início e termo de cada período de trabalho". Nessa modalidade, estabelece o quantum da prestação e o seu quando, ficando estabelecida a sucessão de períodos de trabalhos e períodos de inatividade, uma vez que a duração do trabalho de todo o ano é previamente fixada (MARTINS, 2017). Além disso, a prestação de trabalho não poderá ser inferior a seis meses por ano, dos quais pelo menos quatro meses devem ser consecutivos. (Art. 159, n² da Lei n 7/2009). Como exemplo, cita-se as fábricas de ovos de páscoa e panetones.

Já o trabalho à chamada encontra-se na parte final do Art. 159, n 1 da mesma lei, cuja redação prevê que seja escolhido antes a "antecedência com que o empregador deve informar o trabalhador do início" das atividades. A antecedência citada por esse artigo não deve ser inferior a 20 dias. (Art. 159, n³ da Lei $n^{\circ}$ 7/2009).

Estamos assim perante uma modalidade de contrato de trabalho de acordo com a qual se atribui ao empregador a faculdade de determinar livremente o se e o quando da prestação, ficando o trabalhador num aparente "estado de sujeição", uma vez que, no compromisso contratual que assumiu, se obrigou não só a estar disponível, como também a efectivamente responder às convocatórias do empregador, sendo também especialmente compensado por essa situação de heterodisponibilidade. (MARTINS, 2017).

A modalidade de trabalho à chamada possui características que aproximam da modalidade do trabalho intermitente no Brasil, como a incerteza em relação ao período de prestação de serviço e o tempo de trabalho, que depende exclusivamente da necessidade do empregador, transmitindo para o empregado a incerteza da atividade exercida. 
Após realizar a diferenciação entre as submodalidades do contrato de trabalho intermitente português, torna-se necessário apresentar os requisitos essenciais para a configuração dessa modalidade contratual. Segundo Natasha Schneider (2017) são três os requisitos para que o contrato de trabalho intermitente seja válido: o trabalhador ter um contrato por tempo indeterminado; o empregador exercer uma atividade descontínua ou de intensidade variável; e o trabalho ser realizado com períodos de inatividade remunerada.

A descontinuidade a ser considerada poderá ser de forma total ou parcial, sempre observando um período anual. Em relação a intensidade variável, essa deve ser efetivamente prevista. (MARTINS, 2017). "Percebe-se, portanto, que situações pontuais de crise não caracterizam atividade de intensidade variável, e não autorizam a utilização da modalidade contratual ora analisada". (SCHNEIDER, 2017, p. 61). Por fim, o legislador português preocupou-se em estabelecer períodos mínimos de inatividade, sendo essa remunerada, diferentemente do Brasil, no qual o período de inatividade do trabalhador não é remunerado, utilizando-se da justificativa da não subordinação por parte do empregado.

Outro ponto a ser observado é a remuneração dos trabalhadores intermitentes. A Lei $n^{\circ}$ 7/2009 dispõe em seu artigo 160 o percentual mínimo de compensação retributiva, denominação utilizada para identifıcar a remuneração recebida pelo período de inatividade do trabalhador. Essa deverá ser acordada em instrumento coletivo, ou em sua falta, o valor de $20 \%$, caso a porcentagem seja maior que o mínimo previsto, não há necessidade de acordos coletivos. (SCHNEIDER, 2017).

Segundo Martins (2017) a compensação retributiva se justifica devido a disponibilidade do trabalhador. Em relação ao trabalho à chamada tem-se a heterodisponibilidade, uma vez que aquele fica disponivel ao empregador até a sua convocação, que poderá ocorrer a qualquer momento. Assim dispõe (Carneiro apud Schneider ,2017, p. 66): “Este tempo em que o assalariado não está a trabalhar por conta do seu 
empregador, mas deve permanecer disponível para responder à chamada não é tempo livre nem tempo de trabalho".

Já no trabalho alternado, fala-se em autodisponibilidade, pois o trabalhador não se encontra à disposição do empregador, uma vez que já se sabe exatamente quando deverá retornar ao trabalho. Além disso, o trabalhador intermitente tem direito ao subsídio de natal e de férias. Os termos do cálculo desses subsídios estão estabelecidos no item 2 do Art. 160 da Lei $n^{\circ}$ 7/2009, e devem se dar considerando a média das retribuições e compensações retributivas dos últimos doze meses, considerando contraordenação grave o não cumprimento deste termo.

[...] as parcelas são apuradas a partir da média obtida considerando-se tanto as retribuições pagas ao trabalhador quanto as compensações retributivas, e não a apenas a remuneração dos períodos efetivamente laborados. (SCHNEIDER, 2017).

Os trabalhadores intermitentes possuem direitos e deveres, que estão previstos na Lei $n^{\circ}$ 7/2009 e permanecem durante o período de inatividade: "durante o período de inactividade, mantêm-se os direitos, deveres e garantias das partes que não pressuponham a efectiva prestação de trabalho. "Segundo entendimento de Martins (2017) é o que ocorre, por exemplo, no impedimento do exercício de atividades concorrentes com a do seu empregador. No trabalho à chamada, além dos direitos, verifica-se a total disposição do trabalhador e a obrigação de realizar o trabalho ofertado, que poderá ser convocado para o trabalho a qualquer momento.

Em relação a forma do contrato de trabalho, a supracitada lei dispõe sobre os seus requisitos de validade. Assim como no Brasil, o contrato de trabalho intermitente está sujeito a forma escrita, e deve conter: a identificação, assinaturas e domicílio ou sede das partes; e indicação do número anual de horas de trabalho, ou do número anual de dias de trabalho a tempo completo. Quando não observado a forma prescrita em lei, considera-se que o contrato foi celebrado sem intermitência. (Art. 158 da Lei ${ }^{\circ}$ 7/2009). 
Por fim, a Lei n7/2009 é omissa em relação ao período de férias dos trabalhadores, surgindo uma grande dúvida entre em qual período as férias poderiam ser iniciadas. Segundo Natasha Schneider (2017) as férias devem ser concedidas fora dos períodos previstos para prestação do trabalho, uma vez que, é neste período que os empregadores necessitam de mão de obra. Entretanto encontra-se um grande problema nos casos de pluriemprego, comumente utilizado para compor a renda mensal do trabalhador, a fim de receber o salário integral. [...] "na prática inviabilizaria as férias do trabalhador violando o seu direito ao repouso e desvirtuando a finalidade das férias." (SCHNEIDER, 2017).

\section{Trabalho intermitente inglês}

Chamado de zero hour contract, o contrato de trabalho intermitente no Reino Unido - como o próprio nome já diz - não oferece uma garantia de um mínimo de horas a serem trabalhadas, de modo que os empregados são requisitados conforme a demanda do empregador. Assim, a referida modalidade contratual é bastante utilizada em serviços cuja a demanda é sazonal.

Segundo Lorena Colnago (2018) o contrato zero hora "[...] é aquele que impõe a disponibilidade do trabalhador 24 horas por dia, outorgando as cláusulas e condições contratuais ao empregador [...]". Por isso, o empregado encontra-se em uma situação de vulnerabilidade e instabilidade diante da hipótese de ficar por longos períodos sem ser convocado - e, por conseguinte, sem receber salário - e sem que a empresa sequer precise despedi-lo.

A regulamentação dessa modalidade contratual é feita pela Lei dos Direitos do Emprego de 1996 - Employment Rights Act em seu artigo 27-A. Segundo o dispositivo, o contrato zero hora tem como características a não garantia de recebimento do salário e a não garantia de prestação de serviços (UK, 1996).

Assim como a legislação brasileira, o regramento inglês não prevê como será prestado o serviço, o que fica ao alvedrio das partes 
contratantes. Além disso, o trabalhador poderá ser convocado para o trabalho a qualquer hora.

A escassa regulamentação do contrato de trabalho intermitente no Reino Unido, porquanto não disciplina de maneira satisfatória o contrato, deixa o empregado à mercê do empregador. Segundo o Escritório de Estatísticas Nacionais - Office for National Statistics, os empregados contratados na modalidade intermitente recebem, aproximadamente, 2,5 vezes menos que os empregados de contratos convencionais. Ao passo que o trabalhador convencional aufere um rendimento médio de 479 libras semanais, os trabalhadores intermitentes percebem menos da metade desse valor: 188 libras por semana (ZERO, 2017, p. 1).

Ao que tudo indica, o ordenamento brasileiro apropriou-se das condições do trabalho intermitente inglês, o zero hour contract, uma vez que se aproxima do modelo de precarização ali adotado, períodos de inatividade sem remuneração, risco da atividade econômica assumidos pelo trabalhador, além da remuneração menor do que praticada para os trabalhadores com contratos indeterminados.

\section{Trabalho intermitente espanhol}

A modalidade intermitente presente no direito espanhol recebe o nome de trabajo discontínuo, e diz respeito a um trabalho realizado de modo cíclico e com prazo indeterminado, cujas datas da prestação de serviços são certas e se repetem periodicamente. Desde logo percebe-se que essa modalidade se difere da modalidade de contratos eventuais ou temporários, já que esses últimos se caracterizam pela incerteza e extraordinariedade da prestação dos serviços.

Segundo Lorena Colnago (2018), "[...] estima-se que atualmente sejam mais de duzentos mil trabalhadores espanhóis submetidos a esses contratos para postos de trabalho que não existem por todo ano, mas em datas certas como no verão [...]". Assim, de modo semelhante à modalidade inglesa, o trabajo discontínuo atende à sazonalidade da demanda, em especial no ramo de turismo e hotelaria. 
Quanto à convocação dos empregados, essa se dá respeitando-se a "ordem de antiguidade do trabalhador" (COLNAGO, 2018), e também não atendem à uma exclusividade, podendo os empregados desempenharem outra ocupação nos períodos de inatividade.

Aponta Lorena Colnago:

Há previsão de negociação coletiva com os entes sindicais convenios colectivos - para a celebração entre empresa e trabalhador do contrato parcial, ou seja, dependendo da característica do setor econômico de atuação as entidades sindicais podem criar normas coletivas prevendo contrato fixo descontinuo a prazo temporário, porém, com requisitos objetivos e possibilidade de conversão de contrato temporário para fixos descontínuos. A inexistência dessa negociação coletiva e assinatura de acordos e convenções - na nomenclatura brasileira - implica a caracterização da fraude para esse tipo de contratação. (COLNAGO, 2018, p.29).

Nota-se a presença das entidades sindicais na contratação coletiva de determinadas categorias profissionais, o que busca atenuar a hipossuficiência do empregado quando das negociações do contrato.

\section{Considerações finais}

O instituto do trabalho intermitente, inaugurado no Brasil com a Reforma Trabalhista, Lei n. 13.467/2017, trouxe mudanças no panorama do Direito do Trabalho.

A referida modalidade caracteriza-se, primordialmente, pela não-eventualidade da prestação de serviços. Tal característica a diferencia das demais modalidades de trabalho, uma vez que, presente a eventualidade nas demais formas de trabalho, não há a presença do vínculo empregatício.

Numa perspectiva comparada, analisando-se a regulamentação do trabalho intermitente nos ordenamentos jurídicos italiano, português, inglês e espanhol, nota-se que, a despeito das diferenças de regulamentação, em todos eles o trabalhador encontra-se numa posição de vulnerabilidade e insegurança. 
Levando-se em conta o atual panorama de flexibilização, nota-se que o instituto do trabalho intermitente contribui para a precarização das relações de trabalho. O trabalho intermitente, apesar de diminuir os índices de informalidade, não confere ao trabalhador a dignidade que Ihe é constitucionalmente garantida. É mais um instrumento de dominação do poder econômico, por meio do qual o empregado submete-se ao livre alvedrio do empregador, sem ter a contrapartida da estabilidade salarial justa e necessária para a própria reprodução social.

Por fim, é importante o registro de que os pontos evidenciados neste texto corroboram para o questionamento quanto à constitucionalidade do instituto do trabalho intermitente no ordenamento jurídico brasileiro, prova disso é que sobre este tema estão em tramite no âmbito do Supremo Tribunal Federal, três ações diretas de inconstitucionalidade. A ADI 5826, ajuizada pela Federação Nacional dos Empregados em Postos de Serviços de Combustíveis e Derivados de Petróleo, a ADI 5829, ajuizada pela Federação Nacional dos Trabalhadores em Empresas de Telecomunicações e Operadores de Mesas Telefônicas, e a ADI 6154 ajuizada pela Confederação Nacional dos Trabalhadores na Indústria, ações que até a data de fechamento desta edição, 30 de janeiro de 2021, não haviam sido julgadas.

\section{Referências}

BRASIL. Lei n. 13.467, de 13 de julho de 2017. Altera a consolidação das leis do trabalho (CLT), aprovada pelo Decreto-Lei $n^{\circ} 5.452$, de $1^{\circ}$ de maio de 1943 , e as Leis $\mathrm{n}^{\circ}$ 6.019, de 3 de janeiro de 1974, 8.036, de 11 de maio de 1990, e 8.212, de 24 de julho de 1991, a fim de adequar a legislação às novas relações de trabalho. Disponível em: < http://www.planalto.gov.br/ccivil_03/_ato20152018/2017/lei/l13467.htm>. Acesso em: 29 de janeiro de 2020.

BRASIL Decreto-Lei $n^{\circ} 5.452$, de $1^{\circ}$ de maio de 1943. Aprova a consolidação das leis do trabalho. Disponível em: < http://www.planalto.gov.br/ccivil_03/ decreto-lei/del5452.htm >. Acesso em: 15 de janeiro de 2020.

BRITO, Marcelo Palma de. Posição Legal: art. 443, caput e $\$ 3^{\circ}$, da CLT. In. FONSECA, Rodrigo Dias da. Reforma trabalhista comentada: Lei $n^{\circ}$ 13.467/2917: análise de todos os artigos. Florianópolis (SC): Empório do Direito, 2017. 
COLNACO, Lorena de Mello Rezende. Trabalho intermitente - trabalho "zero hora" - trabalho fixo descontínuo. Revista eletrônica [do] Tribunal Regional do Trabalho da 9 a Região, Curitiba, PR, v. 8, n. 74, p. 27-35, dez. 2018/ jan. 2019. Disponivel em: < https://juslaboris.tst.jus.br/bitstream/handle/20.500.12178/123410/2019_colnago_lorena_trabalho_intermitente.pdf?sequence=1\&isAllowed $=\mathrm{y}>$ Acessado em dezembro de 2020.

COLUMBU, Francesca. O trabalho intermitente na legislação laboral italiana e brasileira. São Paulo: Revista dos Tribunais, vol. 984/2017, p. 277-301, out. 2017. Disponível em < https://revistas.anchieta.br/index.php/Dirdotrabalhoeprocessodotrabalho/article/view/1424> Acesso em fevereiro de 2020.

D' AMORIM, Mariana Correia. O Contrato de trabalho intermitente. Disponível em: < https://repositorio.ufba.br/ri/bitstream/ri/26304/1/Mariana\%20 Correia\%20D\%27Amorim.pdf >. Acesso em: 10 de fevereiro de 2020.

DELCADO, Mauricio Godinho. Curso de direito do trabalho. $16^{\mathrm{a}}$. ed. rev. e ampl. São Paulo (SP): LTr, 2017.

ITÁLIA, D.Lgs. 15 giugno, 2015, n.81. Disciplina organica dei contratti di lavoro e revisione dela normativa in tema di mansioni, a norma dell' articolo 1 , comma 7, dela legge 10 dicembre 2014, n. 183. Disponível em < https://www. cliclavoro.gov.it/Normative/Decreto_Legislativo_15_giugno_2015_n.81.pdf> Acesso em 12 fevereiro de 2020.

ITÁLIA, D.Lgs. 10 settembre 2003, n. 276 Attuazione delle deleghe in materia di occupazione e mercato del lavoro, di cui alla legge 14 febbraio 2003, n. 30. Disponível em < http://www.di-elle.it/leggi-voce-menu/174-d-lgs-276-03-attuazione-I-30-03-legge-biagi-aggiornato-alla-I-92-12> Acesso em 3 fevereiro de 2020.

JORGE NETO, Francisco Ferreira; CAVALCANTE, Jouberto de Quadros Pessoa. Direito do trabalho. 9. ed. São Paulo (SP): Atlas, 2019.

KALED, Gabriela Schellenberg Pedro Bom. Contrato de trabalho intermitente. Curitiba, PR: Anais do VIII CONBRADEC, vol. 1, n. ${ }^{\circ} 28$, p. 39-55, 2019. Disponível em <http://revista.unicuritiba.edu.br/index.php/percurso/article/ view/3418> Acesso em 10 fevereiro de 2020.

LEITE, Carlos Henrique Bezerra. Curso de direito do trabalho. 9. ed. São Paulo (SP): Saraiva, 2018.

MARTINS, André Almeida. O trabalho intermitente como instrumento de flexibilização da relação laboral: o regime do código de trabalho. Leiria: Insti- 
tuto Politécnico de Leiria - Escola Superior de Tecnologia e Gestão, 2012. pp. 66-97. Comunicação apresentada no "I Congresso Internacional de Ciências Jurídico-Empresariais, 2009". Disponível em: < https://iconline.ipleiria.pt/ handle/10400.8/772 >. Acesso em: 08 de dezembro de 2020.

NOGUEIRA, Eliana dos Santos Alves. O contrato de trabalho intermitente na reforma trabalhista brasileira: contraponto com o modelo italiano. Campinas, SP: Revista do Tribunal Regional do Trabalho da $15^{a}$ Região, n. 51, p. 127-148, jul./dez. 2017. Disponível em < https://hdl.handle.net/20.500.12178/125435> Acesso em 15 fevereiro de 2020.

PORTUGAL. Lei n. ${ }^{\circ}$ 7/2009 de 12 de Fevereiro. Aprova a revisão do Código do Trabalho. Disponível: < https://dre.pt/pesquisa/-/search/602073/details/ maximized >. Acesso em: 11 de dezembro de 2020.

PORTUGAL. Lei $n^{\circ}$ Lei $n .^{\circ} 4 / 2008$ de 7 de Fevereiro. Aprova o regime dos contratos de trabalho dos profissionais de espectáculos. Disponível em: < https://dre.pt/web/guest/pesquisa/-/search/248247/details/normal?p_p_ auth=jgsOD3Fb\#: : :text=1\%20\%2D\%20A\%20presente\%20lei\%20regula,produtora\%20ou\%20organizadora\%20desses\%20espect\%C3\%A1culos >. Acesso em 10 de dezembro de 2022.

SCHNEIDER, NATASHA. O Contrato de trabalho intermitente no direito português e a introdução desta modalidade contratual no direito brasileiro através da Lei 13.467/2017. Universidade de Lisboa: sistema integrado de bibliotecas repositório, 2017. Disponivel em: < https://repositorio.ul.pt/handle/10451/37332 >. Acesso em: 09 de dezembro de 2020.

TEIXEIRA, Marilane Oliveira et al. Contribuição crítica à reforma trabalhista. Campinas (SP): CESIT/IE/Unicamp, 2017.

UK. Employment Rights Act. Law n 1996 CHAPTER 18, de 22 de maio de 1996. An Act to consolidate enactments relating to employment rights. Disponível em: < http://www.legislation.gov.uk/ukpga/1996/18/contents >. Acesso em dezembro de 2020.

ZERO, Marcelo. Alguns Dados sobre o Trabalho Intermitente no Reino Unido. Disponivel em: < http://www.josepimentel.com.br/sites/default/files/notas-tecnicas/alguns-dados-sobre-o-trabalho-intermitente-no-reino-unido. pdf>. Acesso em 09 out. 2019. 


\section{Notas}

1 Resultados de pesquisa desenvolvida no âmbito do Programa de Iniciação Científica da Pró-Reitoria de Pesquisa da Universidade Estadual de Montes Claros PRP/UNIMONTES. Edital 06/2019.

2 Advogado. Doutor em Educação pela FAE/UFMG. Professor do Curso de Direito da UNIMONTES. Docente do Centro Universitário FIPMoc. Docente do Programa de Pós-Graduação em Educação da UNIMONTES- PPGE. BRASIL (BR). Número ORCID: 0000-0002-8903-644.E-mail: leandro.sivla@unimontes.br

3 Discente do Curso de Direito da Unimontes. Pesquisadora do Programa de Iniciação Cientifica da Pró-Reitoria de Pesquisa da Unimontes BRASIL (BR). Número ORCID 0000-0002-0897-2168.Email: giovannamendes2014.gm@gmail.com

4 Discente do Curso de Direito da Unimontes. Pesquisador do Programa de Iniciação Cientifica da Pró-Reitoria de Pesquisa da Unimontes. BRASIL (BR). Número ORCID: 0000-0003-2346-1937. Email: victorrangelsoares@gmail.com 


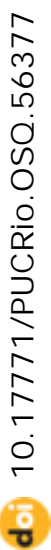

